\title{
Training On Making Perfomed Herbs Jahe Instant In The Village Of Banda Buek The City Of Padang
}

\author{
${ }^{1}$ Rika Sepriani \\ ${ }^{1}$ Fakultas Ilmu Keolahragaan, Universitas Negeri Padang, Indonesia \\ Email: rikasepriani@fik.unp.ac.id ${ }^{1}$
}

\begin{abstract}
Medicinal herb is known as "herbal medicine". Based on the observations that have been made, the community in each house in the village of Bnadar Buat has plants that can be categorized as medicinal plants. They know what plants are used as medicine but the utilization is not optimal because of the lack of knowledge of the public on how to use medicinal plants as traditional medicine appropriately and correctly and how to process them into high economic value products, one of which is the herbal preparation of instant ginger powder. To overcome this, it is necessary to provide information and knowledge as well as training on the preparation of instant ginger powder herbs of high economic value. Before carrying out the activities of the PKM team conducted a socialization stage by inviting PKK mothers in bandar Buat village. This devotional activity uses a way of giving material through lectures, then continued with direct practice by pkk mothers. All participants were involved and each group did its own division of work within the group. From this activity resulted in increased knowledge of PKK mothers about medicinal plants as well as the instigated preparation of instant ginger powder herbs of economic value.
\end{abstract}

Keywords: training, herbal, ginger, instant

\begin{abstract}
Abstrak
Ramuan tanaman obat dikenal dengan sebutan "jamu". Berdasarkan observasi yang telah dilakukan, masyarakat pada setiap rumah di kelurahan Bnadar Buat memiliki tanaman yang dapat dikategorikan sebagai tanaman obat. Mereka mengenal tanaman apa saja yang digunakan sebagai obat namun pemanfaatannya belum optimal karena kurangnya pengetahuan masyarakat tentang cara menggunakan tanaman obat sebagai obat tradisional secara tepat dan benar dan bagaimana mengolahnya menjadi produk bernilai ekonomi tinggi yang salah satunya adalah sediaan herbal jahe serbuk instan. Untuk mengatasi hal tersebut maka perlu dilakukan pemberian informasi dan pengetahuan sekaligus pelatihan tentang sediaan herbal jahe serbuk instan yang bernilai ekonomi tinggi. Sebelum melaksanakan kegiatan tim PKM melakukan tahap sosialisasi dengan mengundang ibu-ibu PKK di kelurahan Bandar Buat. Kegiatan pengabdian ini menggunakan cara pemberian materi melalui ceramah, kemudian dilanjutkan dengan praktik langsung oleh para ibu-ibu PKK. Semua peserta ikut terlibat dan masing-masing kelompok melakukan pembagian kerja sendiri di dalam kelompoknya. Dari kegiatan ini dihasilkan peningkatan pengetahuan ibu-ibu PKK tentang tanaman obat serta dihasilaknnya sediaan herbal jahe serbuk instan yang bernilai ekonomi.
\end{abstract}

Keywords: pelatihan, herbal, jahe, instan

\section{ANALISIS SITUASI}

Meningkatnya kesadaran masyarakat akan kesehatan, berpengaruh pula pada penggunaan obat herbal yang berasal dari tumbuhan dengan cara tradisional dan alami yang sudah dimanfaatkan oleh masyarakat Indonesia dari sejak nenek moyang kita. Hal ini banyak dilakukan masyarakat karena khasiatnya sudah terbukti dapat menyembuhkan penyakit, lebih murah dan efek sampingnya lebih kecil dibandingkan dengan obat-obat modern. Tanaman obat berasal dari tumbuh-tumbuhan baik dari akarnya, daun, buah, bunga dan kulit kayunya (Sepriani, 2018). 
Upaya pengobatan dengan obat-obat tradisonal merupakan salah satu bentuk peran serta masyarakat dan sekaligus merupakan teknologi tepat guna yang potensial untuk menunjang pembangunan kesehatan (Tukiman, 2004). Bangsa Indonesia sudah sejak dulu memanfaatkan hasil alam untuk kelangsungan hidup. Salah satu hasil alam yang telah dikembangkan adalah tumbuh-tumbuhan yang digunakan sebagai obat untuk menyembuhkan berbagai penyakit. Ramuan tanaman obat inilah yang kemudian dikenal dengan sebutan "jamu". Berdasarkan analisis lanjut data Riskesdas 2010, persentase rumah tangga yang menggunakan jamu buatan sendiri sebesar 9,53\% dari 68.673 rumah tangga. Adapun individu yang menggunakan jamu buatan sendiri adalah 10,27\% dari total 177.926 orang. Bahan baku yang paling banyak digunakan adalah kencur, jahe, kunyit dan temulawak (Supardi S, 2010).

Dewasa ini pengobatan secara alami menggunakan tanaman obat sedang menjadi tren di tengah masyarakat kita. Kelurahan Bandar Buat yang merupakan salah satu kelurahan yang terdapat di Kecamatan Lubuk Kilangan dan merupakan pusat dari kecamatan lubuk kilangan dengan luas daerah 2,87 $\mathrm{km}^{2}$ dengan jumlah penduduk 14.649 jiwa. Masyarakat di kelurahan Bandar Buat memiliki mata pencarian yang beragam seperti pedagang, petani, pegawai negeri sipil, pegawai BUMN maupun karyawan swasta. Berdasarkan observasi yang telah dilakukan, masyarakat pada setiap ruamah memiliki tanaman yang dapat dikategorikan sebagai tanaman obat. Mereka mengenal tanaman apa saja yang digunakan sebagai obat namun pemanfaatannya belum optimal karena kurangnya pengetahuan masyarakat tentang cara menggunakan tanaman obat sebagai obat tradisional secara tepat dan benar dan bagaimana mengolahnya menjadi produk bernilai ekonomi tinggi yang salah satunya adalah sebagai jamu serbuk instan

Berdasarkan hal tersebut diatas maka perlu dilakukan pemberian pengetahuan dan informasi kepada masyarakat di kelurahan Bandar Buat tentang penggunaan tanaman obat keluarga (TOGA) sebagai obat tradisional sehingga masyarakat mampu untuk melalukan pengobatan terhadap dirinya sendiri, anggota keluarga ataupun masyarakat dilingkungannnya dengan tepat dan efektif sehingga akan terwujud prinsip kemandirian dalam pengobatan keluarga. Selain itu melalui pembuatan sediaan herbal jahe serbuk instan dengan melibatkan ibu-ibu PKK di Kelurahan Bandar Buat diharapkan mampu meningkatkan nilai ekonomi keluarga yang nantinya dapat dikembangkan menjadi usaha kecil dan menengah di bidang obat-obatan herbal, yang selanjutnya dapat disalurkan ke masyarakat luas. Apalagi dengan maraknya peredaran obat tradisional yang mengandung bahan kimia obat (BKO) di pasaran sehingga dengan membuat sendiri akan lebih meningkatkan keamanan penggunaan obat tradisional bagi masyarakat.

\section{SOLUSI DAN TARGET}

Untuk mengatasi permasalahan yang terjadi pada masyarakat mitra pengabdian di kelurahan Bandar Buat tentang pembuatan sedian herbal jahe serbuk instan maka solusi yang ditawarkan pada kegiatan pengabdian ini adalah:

1. Memberikan informasi dan pengetahuan tentang pemanfaatan tanaman obat sebagai obat tradisional.

2. Memberikan pelatihan tentang pengolahan jahe menjadi sedian herbal jamu serbuk instan yang bernilai ekonomi tinggi.

Adapun target luaran dari kegiatan pengabdian ini adalah:

1. Peningkatan pengetahuan dan pemahaman masyarakat tentang pemanfaatan tanaman obat sebagai obat tradisional 
Journal Humanities: Jurnal Pengabdian kepada Masyarakat Volume 2, Nomor 1, Bulan Juni, 2021. E - ISSN 2715-5471

2. Menghasilkan produk berupa sedian herbal jahe serbuk instan yang siap digunakan sehari-hari dan diproduksi sebagai usaha rumah tangga.

\section{METODE PELAKSANAAN} adalah:

Sesuai dengan tujuan yang ingin dicapai, maka metode kegiatan yang akan diterapkan

1. Metode ceramah dalam penyampaian materi tentang tanaman obat keluarga (TOGA) dan penggunaannya secara tepat dan benar.

2. Metode demonstrasi bagaimana proses pengolahan tanaman obat keluarga (TOGA) jahe menjadi jamu serbuk instan yang memiliki nilai ekonomi tinggi.

3. Melakukan diskusi yang berkaitan dengan pembuatan jahe serbuk instan. berikut ini:

Untuk lebih lengkapnya tahapan kegiatan pengabdian dapat dilihat pada diagram

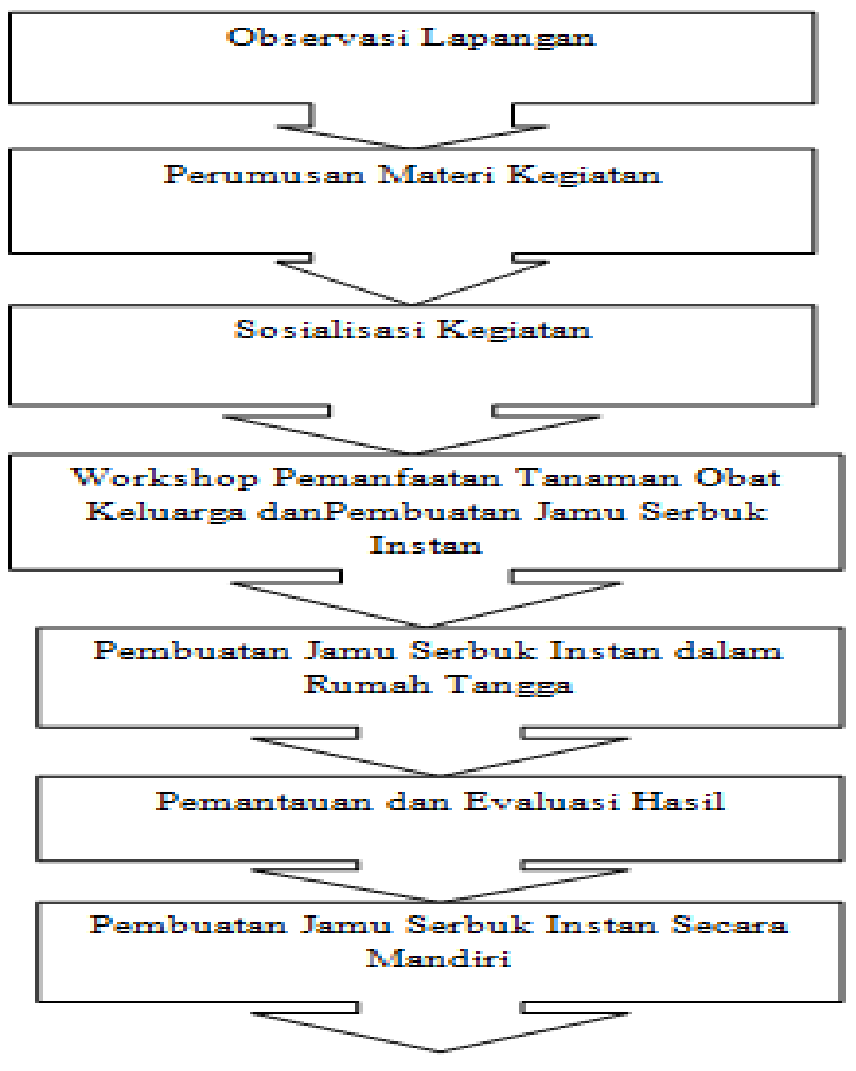

\section{Gambar 1. Tahapan Kegiatan Pengabdian}

Dalam pelaksanaan program pelatihan ini, tim PKM melakukan penyusunan rencana metode yang akan dilakukan selama proses awal sosialisasi dan rencana selama kegiatan berlangsung. Adapun dalam sosialisasi awal, tim PKM terlebih dahulu mengundang ibu-ibu PKK di kelurahan Bandar Buat untuk mensosialisasikan kegiatan yang akan dilangsungkan. Dalam sosialisasi awal, tim PKM memiliki tujuan agar terjadi komunikasi timbal balik tentang bagaimana cara yang efektif untuk mengajak ibu-ibu PKK yang pada umumnya 
adalah ibu rumah tangga yang memiliki kesibukan yang padat dalam rumah tangga dapat ikut serta dalam kegiatan ini.

Kegiatan pengabdian ini menggunakan Metode Training of Trainner (TOT) dengan cara pemberian materi melalui ceramah, kemudian dilanjutkan dengan praktik langsung oleh para ibu-ibu PKK. Cara ini dianggap efektif karena transfer pengetahuan yang diperoleh selama kegiatan akan lebih tersampaikan dengan baik jika peserta itu sendiri yang menyampaikannya dan merasa bahwa kegiatan pengabdian ini bermanfaat bagi mereka.

Dalam kegiatan pengabdian ini, tim PKM membagi peserta menjadi 2 kelompok. Tujuan dari pengelompokkan ini adalah agar kinerja mereka lebih mudah jika dilakukan dengan anggota yang sudah dikenal dengan baik, selain itu diharapkan agar jika nantinya mereka akan menumbuh kembangkan usaha ini di kelurahan mereka, mereka dapat bekerja sama mengelola usaha jamu serbuk instan dari tanaman obat keluarga yang ada di lingkungan masing-masing. Instrumen pelaksanaan masing-masing kelompok tersebut diberikan sama proporsinya, sehingga memudahkan mereka untuk melakukan kegiatan.

Setiap peserta kegiatan juga diharuskan untuk mengaplikasikan materi yang sudah diberikan tim PKM. Semua peserta ikut terlibat dan masing-masing kelompok melakukan pembagian kerja sendiri di dalam kelompoknya. Untuk keberlanjutan kegiatan program ini tim PKM akan terus menjalin komunikasi dengan peserta dan menanggapi setiap masalah yang mereka hadapi dalam proses pembuatan jamu serbuk instan menjadi usaha rumah tangga.

\section{PELAKSANAAN KEGIATAN}

Berdasarkan permasalahan yang dihadapi oleh khalayak sasaran maka tim Pengabdian merumuskan beberapa kegiatan sebagai berikut:

\section{Pemberian materi}

Pemberian materi dilakukan dengan menggunakan metode ceramah kepada ibu-ibu PKK di Kelurahan Banda Buek Kota Padang. Hal ini bertujuan untuk meningkatkan pengetahuan ibu-ibu PKK tentang tanaman obat dan penggunaan tanaman obat secara tepat dan benar.

Pemberian materi dilakukan dengan menggunakan media audiovisual dengan menggunakan proyektor. Materi yang diberikan terkait tanaman obat adalah tentang:

1. Jenis tanaman yang dapat digunakan sebagai obat

2. Cara pengolahan tanaman obat yang tepat

3. Cara penggunaan dan waktu penggunaannya yang tepat sesuai tujuan terapinya

4. Dosis atau takaran penggunaannya sesuai dengan tujuan terapinya 
Journal Humanities: Jurnal Pengabdian kepada Masyarakat Volume 2, Nomor 1, Bulan Juni, 2021. E - ISSN 2715-5471 Doi: https://doi.org/10.24036/jha.0201.2021.05

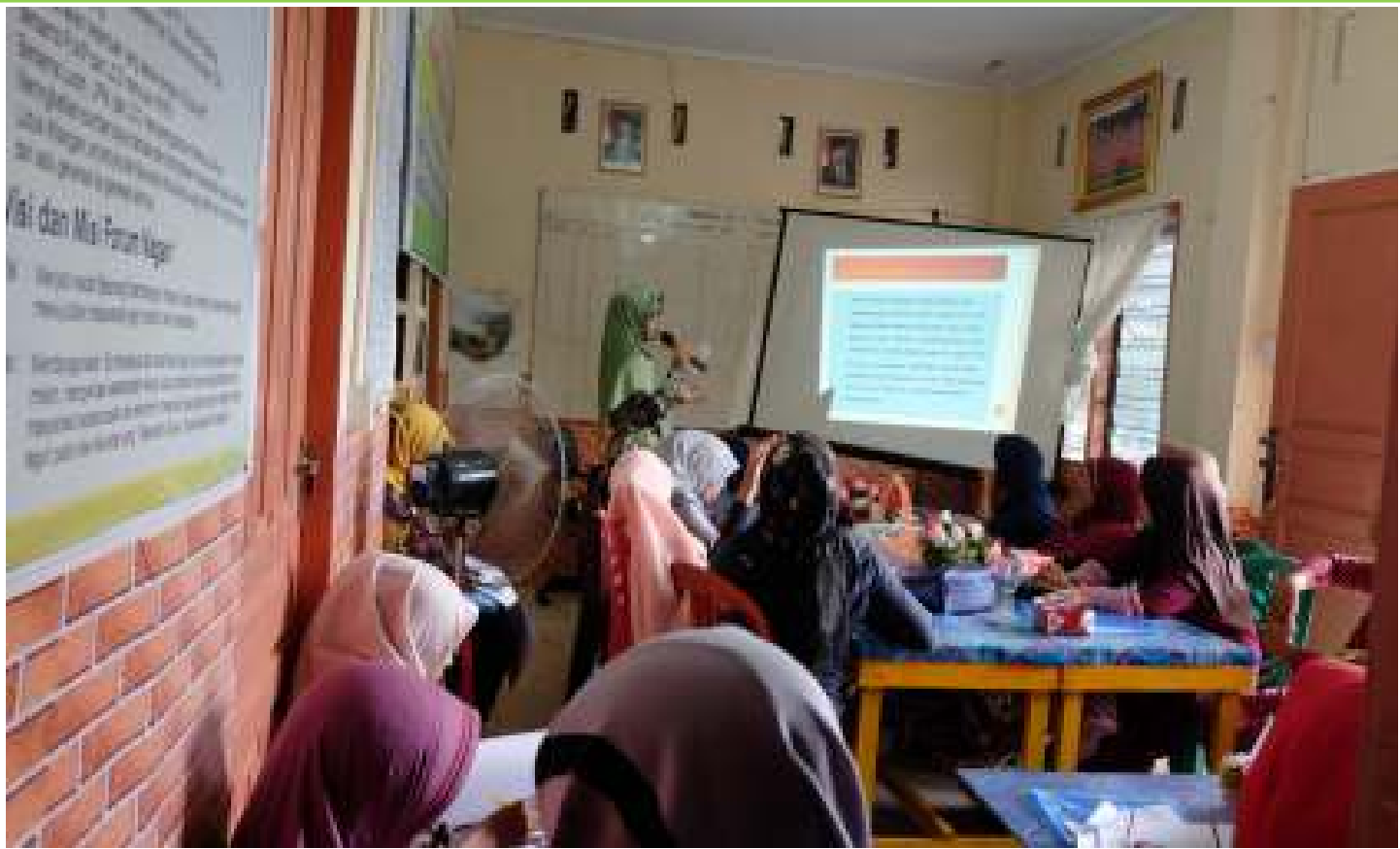

Gambar 2. Narasumber Memberikan Materi

\section{Kegiatan Pelatihan}

Kegiatan pelatihan dilakukan melalui demonstrasi cara pembuatan jamu serbuk instan berbasis tanaman obat keluarga (TOGA) kepada peserta kegiatan pengabdian. Hal ini bertujuan agar para peserta dapat lebih memahami bagaimana cara pengolahan tanaman obat menjadi produk bernilai ekonomi yaitu jamu serbuk instan.

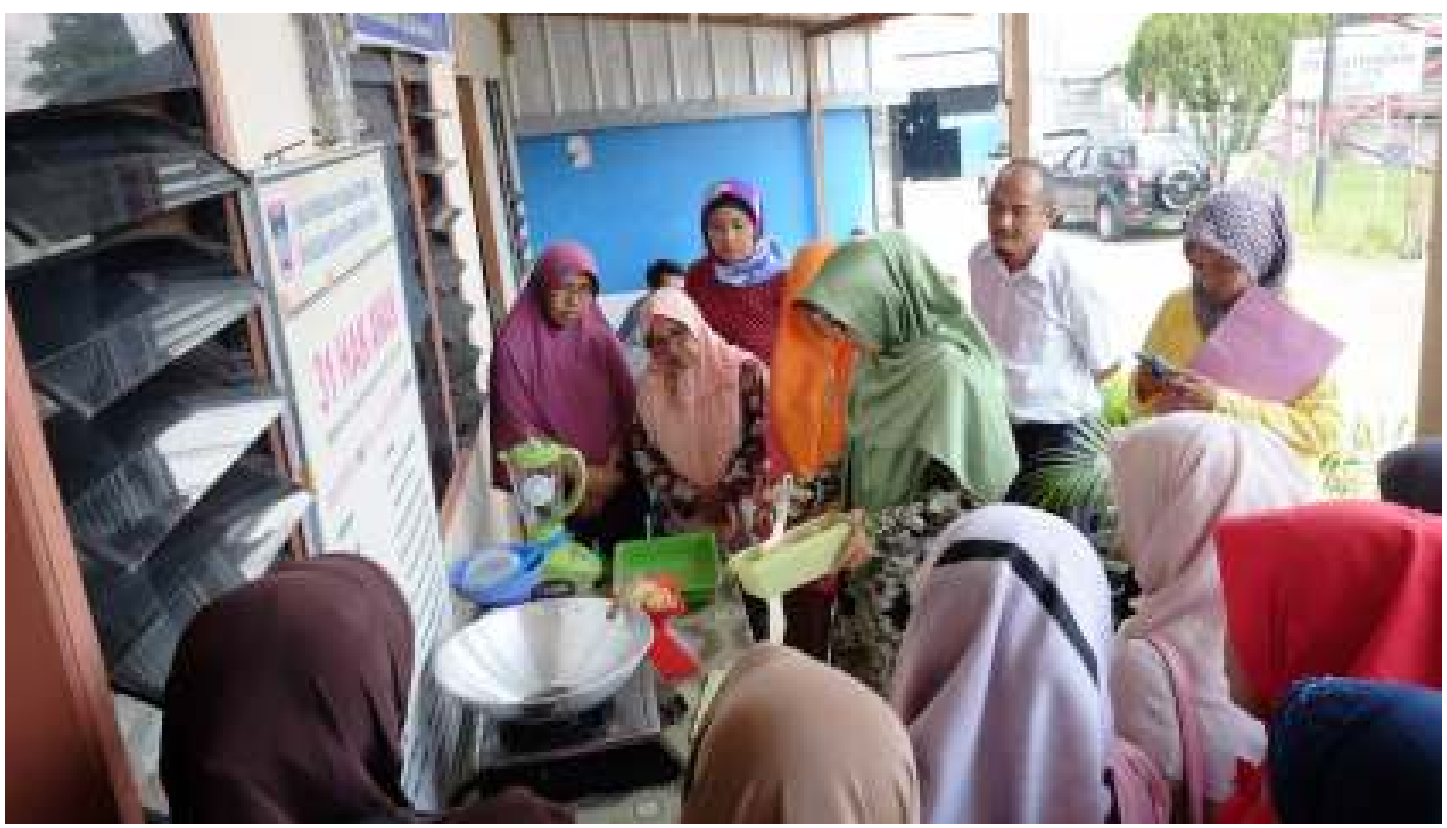

Gambar 3. Proses Pembuatan Sedian Herbal Jahe Serbuk Instan

\section{Kegiatan Pendampingan}

28 Penggunaan artikel akan diatur oleh Lisensi Creative Commons Attribution ShareAlike seperti yang saat ini ditampilkan di Creative Commons Attribution - Lisensi Internasional ShareAlike 4.0 (CC BY-SA). 
Agar keberlanjutan kegiatan ini tetap terjaga, tim pengabdian melakukan kegiatan pendampingan kepada peserta. Tim selalu menyediakan waktu jika ada permasalahan yang dihadapi peserta dalam mengolah jahe menjadi sedian herbal jahe serbuk instan yang bernilai ekonomi.

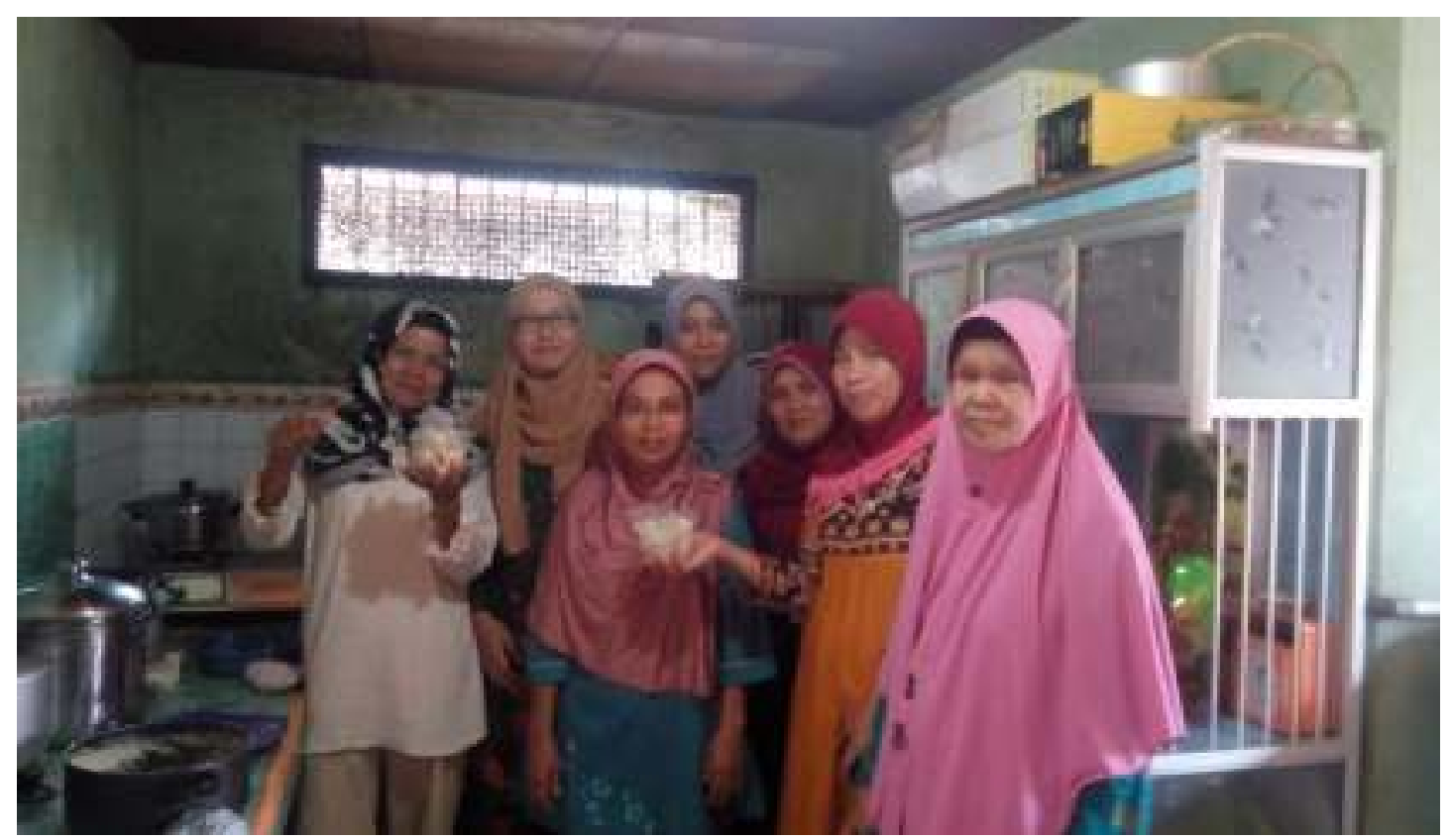

Gambar 4. Kegiatan Pendampingan Kelompok Pengabdian Masyarakat

\section{Evaluasi Kegiatan Pengabdian}

Untuk mengetahui bagaimana ketercapaian kegiatan program pengabdian kepada masyarakat, maka tim dan mitra pengabdian mengadakan diskusi agar kegiatan pengabdian ini dapat lebih baik lagi dimasa yang akan datang dan masyaraka dapat merasakan manfaat dari kegiatan pengabdian ini.

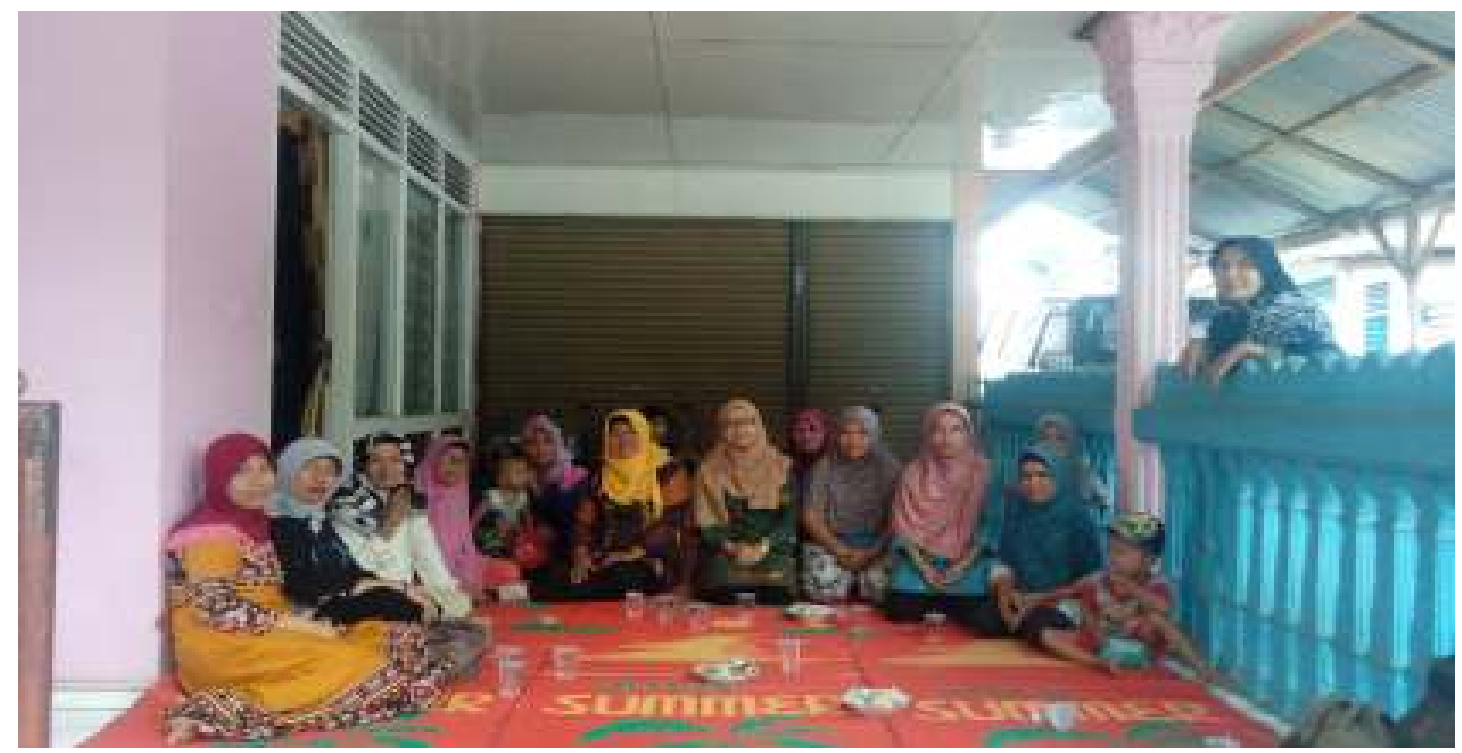

Gambar 5. Evaluasi Kegiatan Pengabdian

HASIL DAN PEMBAHASAN

Penerbit: Jurusan Pendidikan Olahraga, Fakultas Ilmu Keolahragaan, Univ. Negeri Padang

Link: http://jha.ppj.unp.ac.id/index.php/JHA/article/view/38 


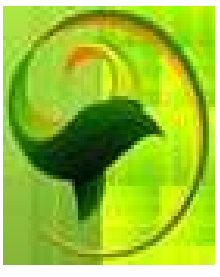

Journal Humanities: Jurnal Pengabdian kepada Masyarakat Volume 2, Nomor 1, Bulan Juni, 2021.

E - ISSN 2715-5471

Doi: https://doi.org/10.24036/jha.0201.2021.05

\section{Hasil}

Berdasarkan pelaksanaan kegiatan pengabdian pelatihan pembuatan sediaan herbal jahe serbuk instan dapat dideskripsikan data sebagai berikut:

1. Ibu-ibu PKK dapat memahami tentang tanaman obat keluarga (TOGA), apa saja tanaman obat keluarga (TOGA) yang sering digunakan dalam kehidupan sehari-hari dan bagaimana cara pengolahannya secara tepat dan benar. Dengan adanya pelatihan ini ibuibu PKK di kelurahan Bandar Buat mampu untuk melakukan swamedikasi secara tepat dan benar menggunakan tanaman obat keluarga (TOGA) terhadap diri sendiri, anggota keluarga ataupun masyarakat sekitar.

2. Ibu-ibu PKK di kelurahan Bandar Buat mampu untuk membuat sediaan herbal jahe serbuk instan yang bernilai ekonomi tinggi. Melalui pembuatan sediaan herbal jahe serbuk instan ini ibu-ibu PKK dapat membuat usaha sendiri dalam skala rumah tangga sehingga mampu meningkatkan perekonomian keluarga.

\section{Pembahasan}

Pemerintah telah menetapkan kebijaksanaan dalam upaya pelayanan kesehatan yaitu Primary Health Care (PHC) sebagai suatu strategi untuk mencapai kesehatan semua pada tahun 2000. Salah satu unsur penting dalam PHC antara lain penerapan teknologi tepat guna dan peran serta masyarakat. Upaya pengobatan tradisional dengan obat-obat tradisional merupakan salah satu bentuk peran serta masyarakat dan sekaligus merupakan teknologi tepat guna yang potensial untuk menunjang pembangunan kesehatan. Hal ini disebabkan antara lain karena pengobatan tradisional telah sejak dahulu kala dimanfaatkan oleh masyarakat serta bahan-bahannya banyak terdapat di seluruh pelosok tanah air (Tukiman, 2004).

Dalam rangka peningkatan dan pemerataan pelayanan kesehatan masyarakat, obat tradisional perlu dimanfaatkan dengan sebaik-baiknya. Untuk lebih meningkat kanpenyelenggaraan pembangunan kesehatan yang semakin luas dan kompleks dengan keputusan Menteri Kesehatan RI No. 99a/Menkes/SK/III/1982 tanggal 2 Maret 1982 telah di tetapkan Sistem Kesehatan Nasional yang merupakan penjabaran pola Pembangunan Nasional dan sebagai petunjuk pelaksanaan pembangunan dibidang kesehatan. Sistem Kesehatan Nasional adalah suatu tatanan yang mencerminkan upaya bangsa Indonesia untuk meningkatkan kemampuan mencapai derajat kesehatan yang optimal sebagai perwujudan kesejahteraan umum. Flora dan fauna serta mineral yang berkhasiat sebagai obat harus dikembangkan dan disebar luaskan agar semaksimal mungkin dapat dimanfaatkan dalam upaya-upaya kesehatan masyarakat. Khususnya untuk tanaman obat penyebaran luasannya dapat dilakukan melalui TOGA (tanaman obat keluarga) (Sepriani et al., 2020).

Penggunaan tumbuh-tumbuhan berkhasiat obat atau lebih dikenal dengan jamu atau herbal sebetulnya sudah lama dikenal oleh masyarakat kita. Walaupun sekarang sudah benyak jamu diproduksi dan dikemas secara modern. Namun tradisi minum jamu secara tradisional masih banyak ditemukan di masyarakat Indonesia, terutama di desa-desa. Jamu sebagai warisan budaya bangsa perlu dikembangkan dan dilestarikan dengan fokus utama pada aspek mutu dan keamanan. Khasiat jamu sebagai herbal selama ini didasarkan pada pengalaman empirik yang telah berlangsung selama kurun waktu yang sangat lama (Shofiah, 2011).

Diantara tanaman obat yang termasuk suku Zingiberaceae, jahe merupakan bahan yang banyak dipakai untuk pembuatan jamu atau obat tradisional. Secara empiris, jahe banyak digunakan masyarakat sebagai obat masuk angin, gangguan pencernaan, anti-piretik, antiinflamasi dan sebagai analgesik. Beberapa hasil penelitian menyebutkan jahe mempunyai senyawa antioksidan. Beberapa komponen bioaktif utama dalam jahe adalah 4- 
Rika Sepriani

diarilheptanoid, shogaol, gingerol dan gingeron memiliki aktivitas antioksidan diatas vitamin E (Shofiah, 2011). Jamu instan dibuat dengan menggunakan tumbuhan obat yang banyak ditanam disekitar rumah (TOGA). Manfaat jamu herbal bagi kesehatan telah dikaji melalui hasil penelitian dan juga termuat pada manuskrip Serat Primbon Jampi Jawi jilid 1, yang menyatakan bahwa ekstrak herbal rimpang kunyit memiliki khasiat untuk menjaga stamina, hepatoprotektor, diuretik, antioksidan, antiradang dan antikanker. Disamping itu jahe, kunyit, kapulaga, laos/lengkuas dan kencur sudah dikenal luas sebagai tanaman biofarma (Made et al., 2020).

Masyarakat di kelurahan Bandar Buat pada setiap rumah memiliki tanaman yang dapat dikategorikan sebagai tanaman obat namun pemanfaatannya belum optimal karena kurangnya pengetahuan masyarakat tentang penggunaan tanaman obat sebagai obat tradisional dan mengolahnya menjadi produk bernilai ekonomi tinggi yang salah satunya sebagai jamu serbuk instan. Kecenderungan masyarakat saat ini adalah lebih suka menggunakan produk yang kemasan dan penyajiannya lebih praktis dan cepat, karena tidak perlu membutuhkan banyak waktu dalam mempersiapkannya.

Pelatihan pembuatan jahe serbuk instan ini dilakukan selama dua hari yaitu pada tanggal 6-7 September 2018 di kelurahan Bandar Buat. Peserta yang mengikuti kegiatan ini sebanyak 25 orang yang merupakan ibu-ibu PKK aktif yang ada di kelurahan tersebut. Ibu-ibu PKK ini tampak begitu antusias mengikuti pelatihan ini karena melalui pelatihan ini mereka mendapatkan informasi dan keterampilan bagaimana melakukan pengolahan jahe menjadi produk bernilai ekonomi yang dapat meningkatkan perekonomian dan derajat kesehatan keluarga. Apalagi dengan maraknya peredaran jamu yang mengandung bahan kimia obat (BKO) di pasaran sehingga dengan membuat sendiri akan lebih meningkatkan keamanan penggunaan obat tradisional bagi masyarakat.

\section{KESIMPULAN}

Berdasarkan pengabdian kepada masyarakat yang telah dilakukan terkait dengan pelatihan pembuatan sediaan herbal jahe serbuk instan di kelurahan Banda Buek Kota Padang dapat ditarik kesimpulan yaitu Ibu-ibu PKK dapat memahami tentang tanaman obat keluarga (TOGA), apa saja tanaman obat keluarga (TOGA) yang sering digunakan dalam kehidupan sehari-hari dan bagaimana cara pengolahannya secara tepat dan benar. Dengan adanya pelatihan ini ibu-ibu PKK di kelurahan Bandar Buat mampu untuk melakukan swamedikasi secara tepat dan benar menggunakan tanaman obat keluarga (TOGA) terhadap diri sendiri, anggota keluarga ataupun masyarakat sekitar. Selain itu, ibu-ibu PKK di kelurahan Bandar Buat mampu untuk membuat sediaan herbal jahe serbuk instan yang bernilai ekonomi. Melalui pembuatan jamu serbuk ini ibu-ibu PKK dapat membuat usaha sendiri dalam skala rumah tangga sehingga mampu meningkatkan perekonomian keluarga.

\section{PENGAKUAN}

Kegiatan pengabdian ini telah di danai oleh Lembaga Penelitian dan Pengabdian Masyarakat (LP2M) Universitas Negeri Padang. Selain itu, kegiatan pengabdian ini juga dibantu oleh Kelurahan Banda Buek dan Ibu-Ibu PKK Kelurahan Banda Buek Kota Padang.

\section{DAFTAR PUSTAKA}

Made, N., Yunica, D., Gde, I. K., Purwantara, T., \& Maryam, S. (2020). Diversifikasi Produk Jamu Serbuk Instan Dari Herbal Usadha Bali. Proceeding Senadimas Undiksha, 14-19.

Sepriani, R.-, Eldawaty, E., Asnaldi, A., Wahyuri, A. S., \& Kibadra, K. (2020). Pembuatan Jamu Serbuk Instan Berbasis Tanaman Obat Keluarga (Toga) Bagi Ibu-Ibu Pkk Di Kelurahan Tarantang Kecamatan Lubuk Kilangan Kota Padang. Jurnal Berkarya Pengabdian Masyarakat, 2(1), 49-55. https://doi.org/10.24036/jba.v2i1.51 
Journal Humanities: Jurnal Pengabdian kepada Masyarakat

Volume 2, Nomor 1, Bulan Juni, 2021.

E - ISSN 2715-5471

Doi: https://doi.org/10.24036/jha.0201.2021.05

Sepriani, R. (2018). PENGETAHUAN DAN PEMANFAATAN TANAMAN OBAT KELUARGA (TOGA) DI KELURAHAN BANDAR BUAT KECAMATAN LUBUK KILANGAN KOTA PADANG. Stamina, 1(1), 279-288.

Shofiah, M. A. (2011). Proses Pembuatan Jamu Serbuk Dari Rimpang Jahe di PJ. Bisma Sehat. Digilib UNS.

Supardi S, S. A. (2010). Penggunaan obat tradisional dalam upaya pengobatan sendiri di Indonesia (Analisis Data Susenas 2007). Buletin Penelitian Kesehatan, 38(2).

Tukiman. (2004). Pemanfaatan Tanaman Obat Keluarga (TOGA) Untuk Kesehatan Keluarga. Bagian Pendidikan Kesehatan dan Ilmu Perilaku Fakultas Kesehatan Masyarakat Universitas Sumatera Utara. USU: Digital Library. 